\title{
Regulation of $\gamma \delta T 17$ cells by Mycobacterium vaccae through interference with Notch/Jagged1 signaling pathway
}

\author{
Yi En Yao ${ }^{1}{ }^{1}$, Jing Hong Zhang $\mathbb{1}^{3}$, Xiao Ju Chen ${ }^{4}{ }^{4}$, Jian Lin Huang ${ }^{1}{ }^{1}$, Qi Xiang Sun $\mathbb{1}^{1}$, \\ Wei Wei Liu (ii) ${ }^{5}$, Huan Zeng (ii) ${ }^{2}$, and Chao Qian Li (i) ${ }^{1}$ \\ ${ }^{1}$ Department of Respiratory Medicine, the First Affiliated Hospital of Guangxi Medical University, Nanning, Guangxi, China \\ ${ }^{2}$ The Second Affiliated Hospital, Guangxi Medical University, Nanning, Guangxi, China \\ ${ }^{3}$ Department of Internal Medicine, Affiliated Tumor Hospital, Guangxi Medical University, Nanning, Guangxi, China \\ ${ }^{4}$ Department of Critical Care, First People's Hospital of Yulin City, Nanning, Guangxi, China \\ ${ }^{5}$ Department of Emergency Medicine, the First Affiliated Hospital of Guangxi Medical University, Nanning, Guangxi, China
}

\begin{abstract}
The objective of this study was to investigate the effect of Mycobacterium vaccae on Jagged 1 and gamma delta T17 ( $\gamma \delta T 17)$ cells in asthmatic mice. An asthma mouse model was established through immunization with ovalbumin (OVA). Gammasecretase inhibitor (DAPT) was used to block the Notch signaling pathway. M. vaccae was used to treat asthma, and related indicators were measured. Blocking Notch signaling inhibited the production of $\gamma \delta T 17$ cells and secretion of cytokine interleukin (IL)-17, which was accompanied by a decrease in Jagged1 mRNA and protein expression in the treated asthma group compared with the untreated asthma group. Similarly, treatment with $M$. vaccae inhibited Jagged 1 expression and $\gamma \delta T 17$ cell production, which was associated with decreased airway inflammation and reactivity. The Notch signaling pathway may play a role in the pathogenesis of asthma through the induction of Jagged1 receptor. On the other hand, the inhibitory effect of $M$. vaccae on Jagged1 receptor in $\gamma \delta \mathrm{T} 17$ cells could be used for the prevention and treatment of asthma.
\end{abstract}

Key words: Asthma; Mycobacterium vaccae; Jagged1 receptor; $\gamma \delta \mathrm{T} 17$; Notch signaling

\section{Introduction}

Bronchial asthma, or simply asthma, is a chronic inflammatory disease of the airways that involves the coordination of various cells including eosinophils, T lymphocytes, mast cells, and neutrophils (1). Despite the progression of asthma-based research, the mechanisms of asthma pathogenesis and progression have not been fully elucidated.

The immunological mechanisms involved in asthma progression have attracted lot of attention over the past decade. One of the classical immunological mechanisms recognized in the world is the Th1/Th2 imbalance (2), in which, the function of Th1 cells is insufficient, and Th2 cells are hyperactive. In this regard, gamma delta $\mathrm{T}(\gamma \delta \mathrm{T})$ cells can play a key role in the regulation of allergic inflammation in the airways. $\gamma \delta T$ are immune cells that have distinctive T-cell receptors (TCR) on their surface, TCR $-\gamma$ and TCR- $\delta$, and play an important role in innate and adaptive immune responses (3). Treatment of mice with anti- $\gamma \delta$ TCR antibodies has been shown to increase serum levels of $\lg \mathrm{E}$, which is known to play a critical role in asthma pathogenesis (4). In addition, $\gamma \delta \mathrm{T}$ cells are an important source of interleukin (IL)-17 (5), which is involved in the recruitment of concentrated granulocytes and participates in the development of various inflammatory diseases $(6,7)$.

IL-17 has been shown to be positively correlated with asthma severity. IL-17 plays a role in regulating inflammation, responsiveness, and airway remodeling $(8,9)$. In addition, it could be a target for gene therapy in hormoneresistant asthma patients (10). In fact, $\gamma \delta T 17$ is a subpopulation of $\gamma \delta \mathrm{T}$ cells that express IL-17 at higher rates, compared to other T lymphocytes (11). Thus, it is necessary to develop new strategies for the treatment of bronchial asthma. In this context, we recently showed that inhaling Mycobacterium phlei reduces lung inflammation in asthma by restoring the balance of $\gamma \delta \mathrm{T}$ and Th1/Th2 cells $(12,13)$. $\gamma \delta \mathrm{T}$ cells can promote airway inflammation and airway hyperresponsiveness by secreting a large arsenal of 
pro-inflammatory cytokines that can modulate Th2mediated pulmonary inflammation (14).

The mechanism of $M$. phlei that regulates $\gamma \delta \mathrm{T} 17$ cells in asthma is not clear. Notch signaling pathway, the main factor that controls lymphocyte activation and differentiation, has been shown to be related to IL-17 (15). Notch signaling pathway plays an important role in the development of asthma by inducing Th2 cell differentiation (16) and may actively maintain a balance of cell types (17). Notch ligand Jagged 1 has been shown to be highly expressed in the proximal asthmatic airways, which may lead to enhanced Th2 cell development $(18,19)$. Many previous findings indicate that it may be possible to treat allergic asthma by inhibiting the production of Th2 and Th17 cytokines and downregulating the expression of Jagged1 (20). Consequently, the mechanism of action of the Notch signaling pathway in asthma has been intensely studied in recent years. However, the role of Notch signaling in the development of $\gamma \delta T 17$ cells in the treatment of asthma using $M$. vaccae is still poorly understood. In this regard, gamma-secretase inhibitor (DAPT) of Notch signaling can regulate Jagged1-Hes1 signaling in mice by blocking the Notch signaling pathway (21). In this work, we used DAPT in an ovalbumin (OVA) asthma model to study the effects of Jagged 1 on $\gamma \delta T 17$ cells during asthmatic inflammation. In addition, we investigated the effect of aerosolized $M$. vaccae on the Jagged1-induced $\gamma \delta T 17$ inflammatory response in an asthmatic mouse model.

\section{Materials and Methods}

\section{Materials}

The materials used were: ovalbumin (OVA) reagent (Sigma, USA); phorbol-myristate actetate (PMA, Sigma); ionomycin (Sigma); aluminum hydroxide gel (Pierce, USA); Mycobacterium vaccae FU22.5 Ug injection (Anhui Zhifeilong Kema Bio-Pharmaceutical Co., Ltd., China); DATP (Selleck, USA), mouse IL-17A ELISA kit (MultiSciences: Wuhan McGee Biotechnology Co., Ltd., China); TRIzol reagent, reverse transcription kit, SYBR Green nucleic acid dye, PCR primer design and synthesis (TakalaRa, Japan); Jagged1 immunohistochemical antibody (CST, USA); flow antibody PerCP-Cy5-5 CD3, APC $\gamma \delta \mathrm{T}$, PE IL-17 (American eBioscience, USA); antibody monensin, fixed/membrane-breaking liquid (BD Co., USA); Finepointe NAM Mouse Noninvasive Lung Function Tester (BUXCO, USA).

\section{Animals and experimental groups}

Healthy male C57 mice (4-6 weeks old; weight $20 \pm$ $2 \mathrm{~g})$ were provided by the Animal Experimental Center of Guangxi Medical University (China) and housed in pathogen-free cages under SPF laboratory conditions. They were maintained in an air-conditioned room with a suitable temperature and humidity, and free access to food and water. Ethical approval was obtained from
Guangxi Medical University Animal Ethics Committee before the study started.

Mice were randomly distributed into five groups containing 8 mice each: control group, asthma group (OVA), blocking group (DAPT + OVA), prevention group ( $M$. vaccae + OVA), and treatment group (OVA + M. vaccae).

\section{Asthma model, prevention, and treatment methods}

The asthma model mice were sensitized by treatment with $25 \mu \mathrm{g}$ of OVA emulsified in aluminum hydroxide gel ( $1 \mathrm{mg}$ ) on days 0,7 , and 14 . The animals were then challenged with $2 \%$ OVA diluted in phosphate-buffered saline (PBS) for 30 min on days 21-28. For the blocking group, the $\gamma$-secretase inhibitor DAPT $(0.3 \mathrm{mg} / \mathrm{kg})$ was inhaled for $30 \mathrm{~min}$ before the OVA treatment. Furthermore, $22.5 \mu \mathrm{g}$ of the $M$. vaccae powder was dissolved in $10 \mathrm{~mL}$ of physiological saline and was given to mice by inhalation on days 21-28 for the prevention group, and on days 28-35 for the treatment group. In the control group, each of the above-mentioned treatments were replaced with the same amount of normal saline. Similarly, treatments for the asthma group were replaced with the same amount of normal saline. Mice were sacrificed by intraperitoneal injection of $10 \%$ chloral hydrate $(0.1 \mathrm{~mL})$, and specimens were collected within $24 \mathrm{~h}$ of the last treatment.

\section{Mouse airway reactivity test}

The mice were placed in test chambers and the ventilator was turned on to detect the specific airway resistance (sRaw) triggered by PBS and different methacholine (Mch) concentrations $(6.25,12.5,25$, and $50 \mathrm{mg} /$ $\mathrm{mL})$.

\section{Lung histopathology}

The left lung tissue was fixed with $4 \%$ paraformaldehyde for $24 \mathrm{~h}$, rinsed, dehydrated in ethanol gradient, and embedded in paraffin. The paraffin sections were then sliced at a thickness of $4 \mu \mathrm{m}$ and stained with hematoxylin and eosin (HE) and with Periodic acid-Schiff (PAS). The sections were observed under a light microscope (Olympus, Japan).

Then, 4-mm paraffin-embedded tissue sections were dewaxed in xylene and rehydrated in graded alcohols. Endogenous peroxidase was blocked using 3\% hydrogen peroxide. Antigen recovery was performed by boiling tissue sections in $10 \mathrm{mM}$ citrate buffer $(\mathrm{pH} \mathrm{6.0)}$ for $10 \mathrm{~min}$. The tissue sections were incubated in $5 \%$ goat serum albumin and subsequently in polyclonal goat anti-human Jagged1 antibody (1:2500; D4Y1R, CST) for $24 \mathrm{~h}$ at $4^{\circ} \mathrm{C}$, Then, the tissue sections were incubated with the horseradish peroxidase-conjugated secondary antibody for 60 min at room temperature, and subsequently stained with 3,3-diaminobenzidine and counterstained with hematoxylin blue. Negative controls were performed by replacing the primary antibody with unimmunized serum. Control tissue sections were treated in parallel with the samples. 
All tissue sections were observed under an optical microscope (Olympus).

The proteins were detected by immunofluorescence assay. For Jagged1 staining, air-dried cryostat sections of lung tissue $(2 \mathrm{~mm}$ ) were fixed using ice-cold methanol for $20 \mathrm{~min}$, air-dried again, incubated in PBS containing $20 \%$ fetal calf serum (FCS) for $10 \mathrm{~min}$, and exposed to $30 \mathrm{~mL}$ of $1.5 \% \mathrm{H}_{2} \mathrm{O}_{2}$ for cell permeabilization. Then, the sections were washed twice with PBS and incubated with an avidin $D$ solution for $10 \mathrm{~min}$. Endogenous peroxidase was blocked using a biotin solution to inhibit endogenous biotin, washed again, and subsequently incubated with rabbit anti-mouse Jagged1 antibody (1:1000; D4Y1R, CST) overnight at $4^{\circ} \mathrm{C}$. Next, the sections were washed twice with PBS, treated with the goat anti-mouse $\lg G$ secondary antibodies for $2 \mathrm{~h}$ in the dark. Finally, the sections were washed and observed by fluorescence microscopy (Olympus).

\section{ELISA test}

Mice were anesthetized with $10 \%$ chloral hydrate, and blood was obtained from the eyeballs. The collected blood was allowed to stand for $3 \mathrm{~h}$ at $25^{\circ} \mathrm{C}$ and centrifuged at $700 \mathrm{~g}$ for $10 \mathrm{~min}$. The supernatant was collected and stored at $-80^{\circ} \mathrm{C}$. The serum concentrations of $\mathrm{IL}-17$ in mice in each group were measured by commercial ELISA kits according to the manufacturer's instructions (MultiSciences: Wuhan McGee Biotechnology Co., Ltd.). The IL-17 ELISA kits detect from 47 to $3000 \mathrm{pg} / \mathrm{mL}$. Absorbance values at $450 \mathrm{~nm}$ were obtained by a micro-plate ELISA reader (BioTek, USA). All samples were analyzed in duplicate and IL-17 concentrations were determined by comparison with the standard curve.

\section{mRNA extraction and qRT-PCR}

TRIzol reagent was used to extract the total RNA from the lung tissues. RNA concentration was detected using absorbance values at $260 \mathrm{~nm}$ obtained on a NanoDrop 2000 (Thermo Fisher Scientific, USA) spectrophotometer. cDNA was prepared by reverse transcription according to the manufacturer's instructions and stored at $-20^{\circ} \mathrm{C}$ until use. Real-time PCR was performed in triplicate using the SYBR Green master mix. The reaction conditions were $95^{\circ} \mathrm{C}$ for $30 \mathrm{~s}, 95^{\circ} \mathrm{C}$ for $5 \mathrm{~s}$, and 40 cycles of $60^{\circ} \mathrm{C}$ for $34 \mathrm{~s}$. The relative change in gene expression was calculated using $2^{-\Delta \Delta C T}$ and GAPDH as an internal reference gene. The following primer pairs were used: GAPDH, upstream primer 5'-TGTGTCCGTCGTGGATCTGA-3', downstream primer 5'-TTGCTGTTGAAGTCGCAGGAG-3'; Jagged1, upstream primer 5'-CCAGCGGTCCTAATGGTGATG-3', downstream primer 5'-GCTGTGGTTCTGAGCTGCAAAG-3'.

\section{Flow cytometry analysis}

The mouse lung tissue was digested in $2 \mathrm{~mL}$ of RPMI 1640 medium (Gibco, USA) containing collagenase IV $(2.5 \mathrm{~g} / \mathrm{L})$ at $37^{\circ} \mathrm{C}$ for $40 \mathrm{~min}$. The cell suspension and the incompletely digested lung and spleen tissue pellet were then ground using a $200 \mu \mathrm{m}$ mesh filter, centrifuged at $250 \mathrm{~g}$ for $5 \mathrm{~min}$ at $4^{\circ} \mathrm{C}$. The supernatant was discarded, and the pellet was incubated in red blood cell lysis buffer for $4 \mathrm{~min}$ in the dark and then centrifuged $(250 \mathrm{~g}$ for $5 \mathrm{~min}$ at $4^{\circ} \mathrm{C}$ ). The supernatant was discarded again, and the pellet was washed with PBS. The magnetic bead cells were separated and cultured in a cell incubator at $5 \% \mathrm{CO}_{2}$ and $37^{\circ} \mathrm{C}$ for $48 \mathrm{~h}$. The retained pellet containing lung mononuclear cells was resuspended at $10^{6}$ cells $/ \mathrm{mL}$ in $1 \mathrm{~mL}$ of RPMI 1640 medium containing $10 \%$ fetal bovine serum, $25 \mu \mathrm{g} / \mathrm{L}$ of PMA, $1 \mu \mathrm{g} / \mathrm{L}$ ionomycin, and $0.2 \%$ monensin. The cell suspension was incubated for $4 \mathrm{~h}$ at $5 \% \mathrm{CO}_{2}$ and $37^{\circ} \mathrm{C}$ and then centrifuged $(250 \mathrm{~g}$ for $5 \mathrm{~min}$ at $\left.4^{\circ} \mathrm{C}\right)$. Percp-Cy5-5 anti-CD3 antibody and APC anti$\gamma \delta \mathrm{T} 17$ antibody were added to the pellet and incubated at $4^{\circ} \mathrm{C}$ for $30 \mathrm{~min}$ in the dark. The cells were then washed with PBS, resuspended in Cytofix/Cytoperm solution (Becton Dickinson, USA), and incubated for $20 \mathrm{~min}$ at $4^{\circ} \mathrm{C}$ in the dark. After that, the cells were rinsed with washing buffer and incubated with PE anti-IL-17 antibody for $30 \mathrm{~min}$, then washed twice with PBS, and resuspended in $200 \mu \mathrm{L}$ of PBS. Flow cytometry analysis was performed using FlowJo 7.6 software (Becton Dickinson).

\section{Statistical analysis}

Statistical analysis was performed using the SPSS 22.0 software (IBM, USA) and the graphics were generated using the Prism 5.0 software (GraphPad, USA). The data are reported as means $\pm S E$. ANOVA was used to analyze the differences among group means, followed by post-hoc Fisher's least significant difference (LSD) test for pairwise comparisons between groups. Pearson correlation was used to measure the correlation between samples. A P-value $<0.05$ was considered statistically significant.

\section{Results}

\section{Mouse airway reactivity}

Figure 1 shows the airway reactivity in the five experimental groups. The airway resistance (sRaw values) of the mice in the asthma group was significantly higher than that of the control group after stimulation with 12.5, 25, and $50 \mathrm{mg} / \mathrm{mL}$ of Mch $(P<0.05)$. The difference between the control group and the blocking, prevention, and treatment groups was also statistically significant $(P<0.01)$. There was no significant difference in airway reactivity among all groups after $6.25 \mathrm{mg} / \mathrm{mL}$ Mch stimulation $(P>0.05)$.

\section{Lung histopathology}

Lung HE and PAS staining showed that the control group had normal bronchial morphology, no hyperplasia of epithelial cells, no thickening of the walls, normal alveolar septum, and few inflammatory cells around the bronchi and blood vessels. PAS staining of control lungs showed a 
very small amount of goblet cells in the airway epithelium and no mucus oozing. Compared to the control lungs, the asthma group lungs showed greater inflammatory cells infiltration around the bronchus and blood vessels, in addition to bronchial lumen stenosis and thickened walls. PAS staining of the asthma group showed goblet cells hyperplasia and more prominent mucus oozing. In comparison with the asthma group, the bronchial and perivascular inflammatory cells infiltration, as well as goblet cells and mucus oozing, were significantly reduced in the blocking, prevention, and treatment groups (Figure 2).

\section{Immunohistochemistry and immunofluorescence}

The expression of Jagged1 in the lung tissue of asthmatic mice increased significantly compared to the

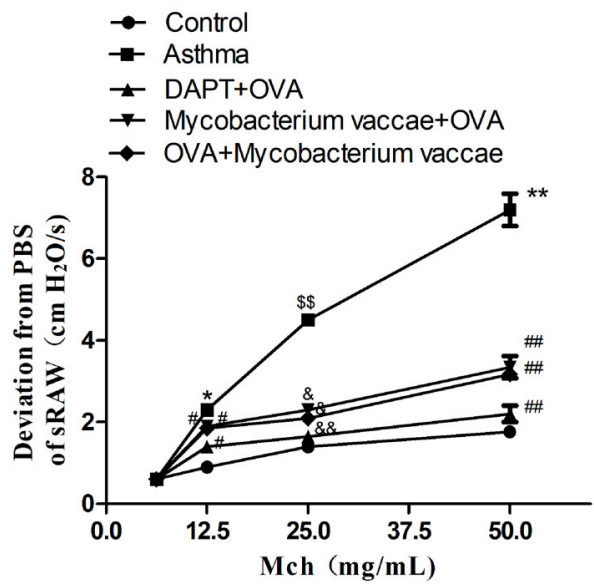

Figure 1. Effects of inhaled inactivated Mycobacterium vaccae on airway hyperresponsiveness with methacholine (Mch) treatment. Airway reactivity was measured using specific airway resistance (sRaw). Ovalbumin (OVA) challenge significantly increased sRaw in all 4 methacholine doses with the maximum increase achieved in the dose $50 \mathrm{mg} / \mathrm{mL}$. Data are reported as mean \pm SE relative percentage to the control group $(n=8) .{ }^{*} P<0.05,{ }^{\$ \$} P<0.01$, ${ }^{* *} \mathrm{P}<0.01$ vs control group; ${ }^{\#} \mathrm{P}<0.05, \quad{ }^{*} \mathrm{P}<0.05,{ }^{\& \&} \mathrm{P}<0.01$, ${ }^{\# \#} \mathrm{P}<0.01$ vs asthma group (ANOVA). control group $(P<0.05)$. Interestingly, the expression of Jagged1 was decreased in the lung tissue of the blocking, prevention, and treatment groups. The difference was statistically significant in the three groups, compared to the asthma group (Figure 3, $\mathrm{P}<0.05$ ).

\section{Jagged1 mRNA expression in mouse lung tissues}

The mRNA expression of Jagged1 in the asthma group was significantly greater than in the normal group $(P<0.01)$. Importantly, the expression of Jagged1 mRNA in the prevention and treatment groups was significantly lower than that in the asthma group (Figure $4, \mathrm{P}<0.05$ ).

\section{IL-17A levels in the serum}

IL-17A levels in the serum were significantly higher in the asthma group, compared to the normal group $(P<0.05)$. In addition, the IL-7A level in the serum of the prevention, treatment, and blocking groups was significantly lower than in the asthma groups (Figure 5, $\mathrm{P}<0.05)$.

\section{Correlation analysis between Jagged 1 and $\gamma \delta$ T17 cells in the lung tissues}

The level of IL-17+ of $\gamma \delta \mathrm{T} 17$ cells in the lung tissues from the asthma group was higher than that of the control group $(P<0.05)$. Interestingly, compared to the asthma group, the ratio of IL-17 $+\gamma \delta \mathrm{T}+$ cells to T cells was lower in the prevention, treatment, and blocking groups (Figures 6 and $7, \mathrm{P}<0.05$ for each group). The percentage of IL-17 $+\gamma \delta \mathrm{T}+$ cells and the mRNA expression of Jagged 1 in the lung tissues was positively correlated $(r=0.46, P<0.05)$. This may suggest that the Notch signaling pathway had a regulatory effect on $\gamma \delta \mathrm{T} 17$ cells in asthmatic mice and that inhalation of inactivated $M$. vaccae can regulate $\gamma \delta T 17$ secretion in asthmatic mice.

\section{Discussion}

IL-17 has a powerful role in recruiting and activating neutrophils, especially in patients with severe asthma and glucocorticoid resistance. IL-17 can aggravate airway

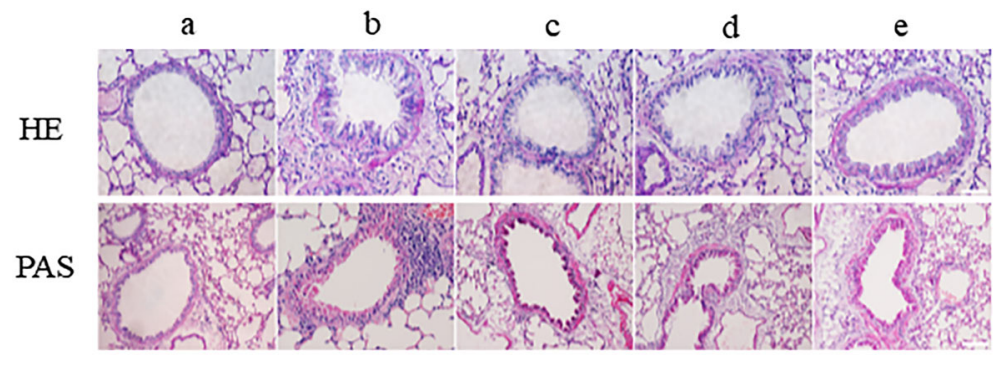

Figure 2. Lung histopathology was detected using hematoxylin and eosin (HE) and Periodic acid-Schiff (PAS) staining. Effects of inactivated Mycobacterium vaccae on ovalbumin (OVA)-induced airway inflammation. Histological examination of normal control group (a), asthma group (b), gamma-secretase inhibitor (DAPT + OVA group (c), M. vaccae + OVA group (d), OVA + M. vaccae group (e). HE staining: original magnification $\times 400$, scale bar $=50 \mu \mathrm{m}$; PAS staining: original magnification $\times 200$, scale bar $=100 \mu \mathrm{m}$. 
A

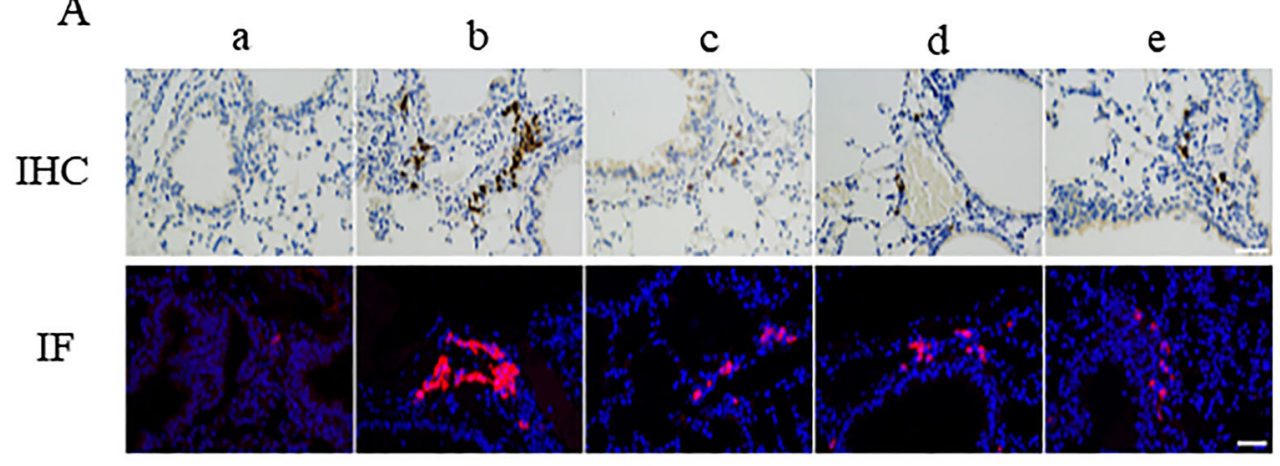

B

Control
Asthma
DAPT+OVA
Mycobacterium vaccae+OVA
OVA+Mycobacterium vaccae

C
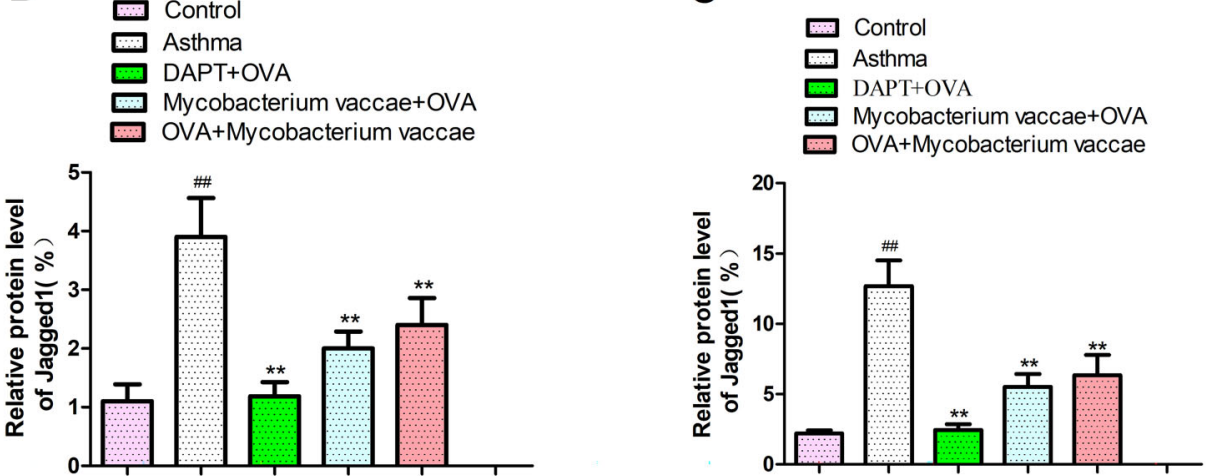

Figure 3. Expression of Jagged1 using immunohistochemical and immunofluorescence stains (A) in mice in control group (a), asthma group (b), gamma-secretase inhibitor (DAPT) + ovalbumin (OVA) group (c), Mycobacterium vaccae + OVA group (d), OVA + M. vaccae group $(\mathbf{e})$, and its quantification (B and $\mathbf{C}$ ). Data are reported as mean $\pm \mathrm{SE}$ relative percentage to the control group ( $\mathrm{n}=8$ ). ${ }^{\# \#} \mathrm{P}<0.01$ vs control; ${ }^{* *} \mathrm{P}<0.01$ vs asthma group (ANVOA). Original magnification $\times 400$, scale bar=50 $\mu \mathrm{m}$.

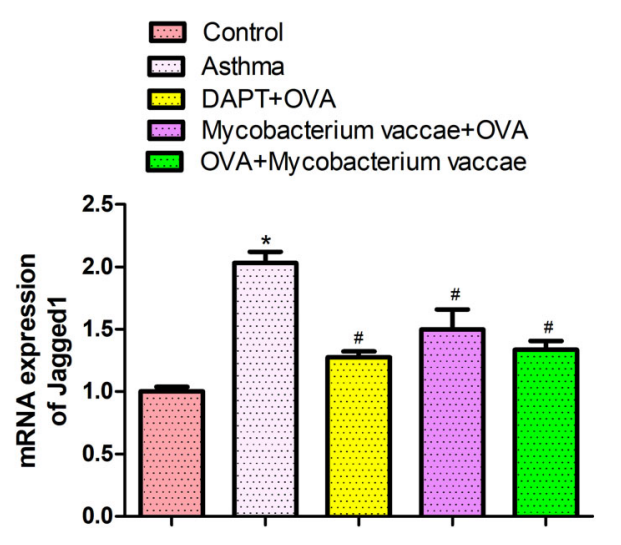

Figure 4. The mRNA expression of Jagged1 in lung tissues was determined using real-time PCR. Data are reported as mean \pm SE relative percentage to the control group $(n=8)$. ${ }^{*} P<0.05$ vs control; ${ }^{\#} \mathrm{P}<0.05$ vs asthma group (ANOVA). OVA: ovalbumin; DAPT: gamma-secretase inhibitor.

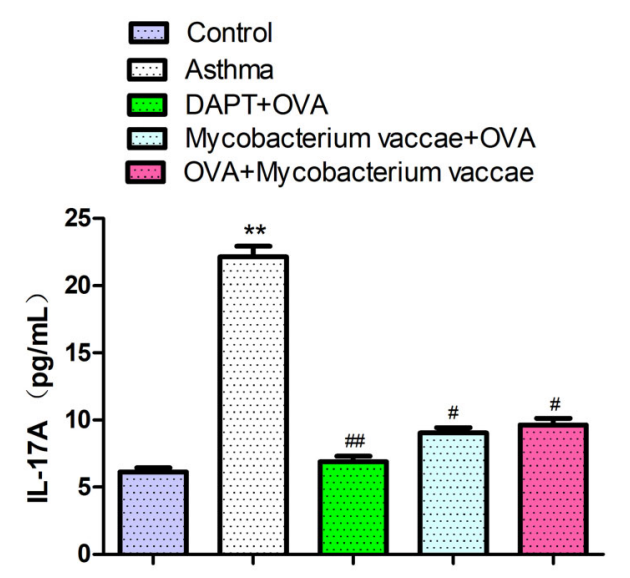

Figure 5. Interleukin (IL)-17A concentrations in serum by ELISA using specific cytokine detection kits. Data are reported as mean \pm SE relative percentage to the control group $(n=8)$. ${ }^{*} P<0.01 \mathrm{vs}$ control; ${ }^{\#} \mathrm{P}<0.05$, ${ }^{\# \#} \mathrm{P}<0.01$ vs asthma group (ANOVA). OVA: ovalbumin; DAPT: gamma-secretase inhibitor. 

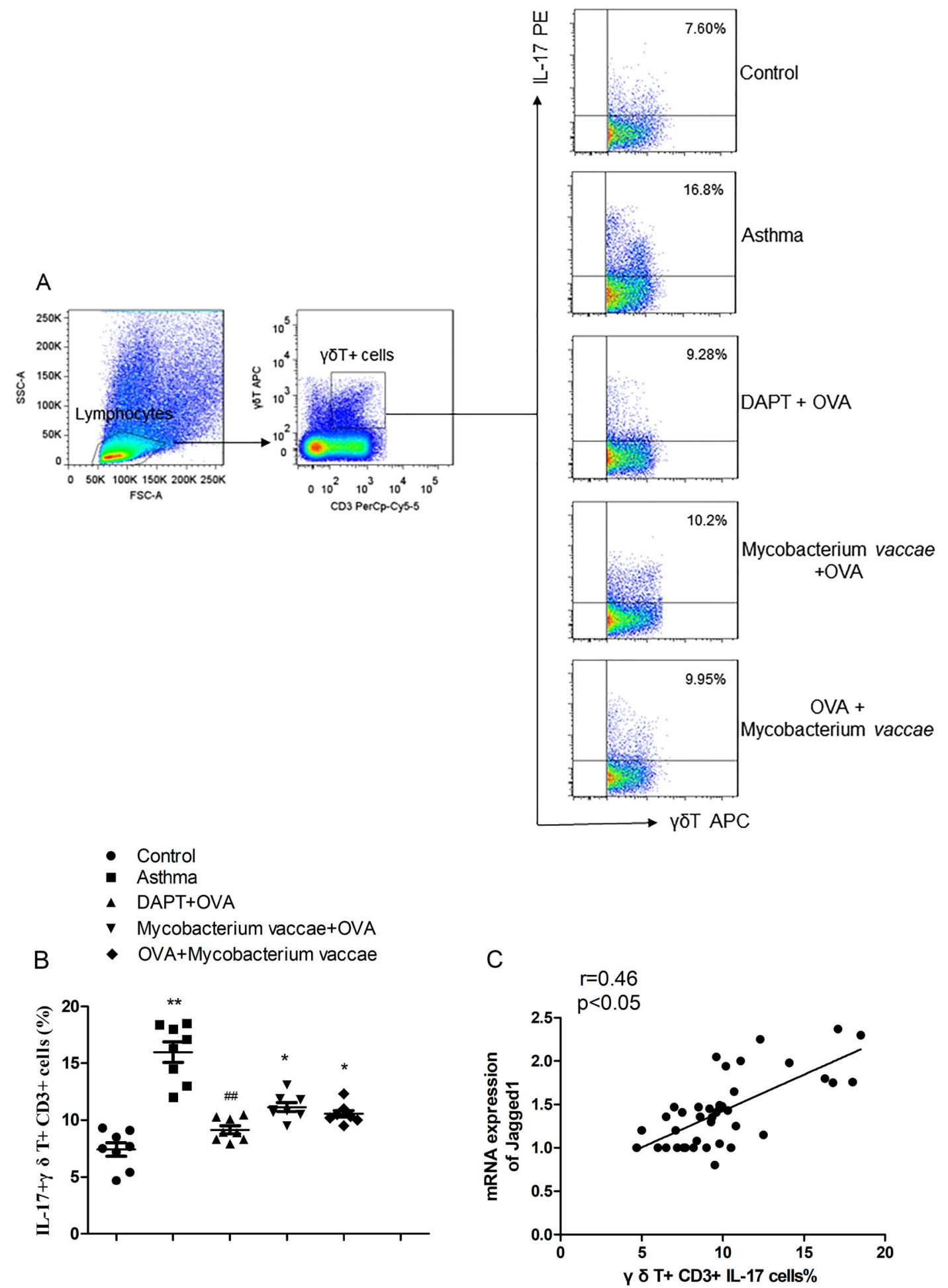

Figure 6. Correlation analysis between Jagged 1 and $\gamma \delta$ T17 cells in lung tissues. A and B, The ratio of IL-17 $+\gamma \delta \mathrm{T}+$ cells to T cells was measured in each group. C. The percentage of IL-17+ $\delta \delta \mathrm{T}+$ cells and the Jagged1 mRNA expression in lung tissues were positively correlated $(r=0.46, P<0.05)$. Data are reported as mean $\pm S E$ relative percentage to the control group $(n=8)$. ${ }^{* *} P<0.01$ vs control; ${ }^{*} \mathrm{P}<0.05,{ }^{\#} \mathrm{P}<0.01$ vs asthma group (ANOVA). OVA: ovalbumin; DAPT: gamma-secretase inhibitor. 


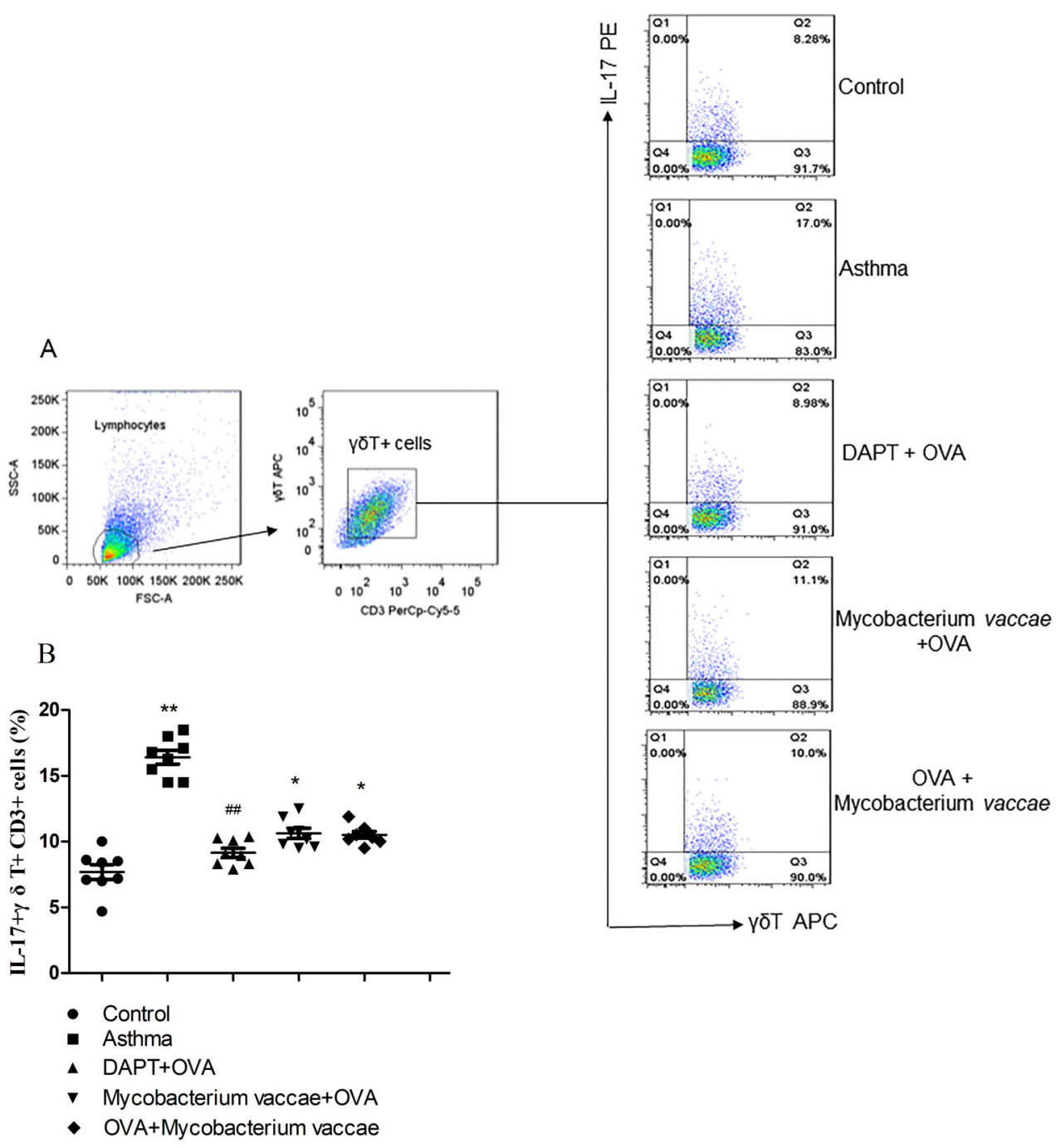

Figure 7. Mycobacterium vaccae spleens from ovalbumin (OVA)-treated mice were compared to the control, asthma, gamma-secretase inhibitor (DAPT) + OVA, M. vaccae + OVA, and OVA + M. vaccae groups to determine the percentage of $\gamma \delta \mathrm{T} 17$ cells among the CD3 + T cells by flow cytometry. Data are reported as mean $\pm S E$ relative percentage to the control group $(n=8)$. * $P<0.01$ vs control; ${ }^{*} P<0.05$, ${ }^{\# \#} \mathrm{P}<0.01$ vs asthma group (ANOVA).

inflammatory cell infiltration and promote airway remodeling and hyperresponsiveness. IL-17 acts directly on epithelial cells to promote goblet cells hyperplasia and mucus gland secretion (22), which in turn promotes pulmonary fibrosis by inducing TGF- $\beta$ and collagen expression (23). $\gamma \delta \mathrm{T}$ cells show an imbalance in Th1/Th2 ratio and evidence suggests that $\gamma \delta \mathrm{T}$ cells are involved in the development of asthma $(4,24)$. $\gamma \delta \mathrm{T}$ cells and memory $\alpha \beta T$ cells produce similar levels of IL-17 (25). $\gamma \delta$ T17 cells induce the production of inflammatory cytokines, promote the release of inflammatory transmitters, and participate in the development of inflammatory reactions. In our study, we showed the role of the Notch signaling pathway in asthma using the Notch inhibitor DAPT. Our results showed that, although IL-17 cytokine expression increased significantly in asthma, the inhibition of Notch signaling decreased airway responsiveness and inflammation in asthmatic mice. In addition, the expression of cytokine IL-17 in $\gamma \delta \mathrm{T} 17$ cells increased significantly in the lungs of asthmatic mice. Interestingly, Jagged1 mRNA expression was positively correlated with the percentage of CD $3+/ \gamma \delta \mathrm{T}+$ cells and IL-17 $+\gamma \delta \mathrm{T}+$ cells in the lungs of mice. This suggested that the expression level of Jagged 1 is closely related to the pathogenesis of asthma. Furthermore, we showed that the expression of $\gamma \delta \mathrm{T} 17$ cell-associated cytokine IL-17 in the spleen of mice decreased significantly in the prevention and treatment groups that used $M$. vaccae. These findings 
indicated that OVA and $M$. vaccae may affect the percentage of $\gamma \delta T 17$ cells in the spleen of animals. Moreover, this may also suggest that the Notch signaling pathway participated in the pathogenesis of asthma by regulating the secretion of IL-17 by $\gamma \delta T 17$ cells through Jagged1 receptor.

We have shown in previous studies that $\gamma \delta \mathrm{T} 17$ cells are involved in the pathogenesis of asthma induction (26), which was confirmed by the presence of an imbalance in the Th1/Th2 ratio of $\gamma \delta$ T cells in asthma animal models (27). Inhalation of $M$. phlei has been shown to correct the Th1/Th2 ratio in asthma $(12,13)$ and reverse the Th1/Th2 ratio of $\gamma \delta \mathrm{T}$ cells thereby reducing lung inflammation. $M$. vaccae and $M$. phlei belong to the genus Mycobacterium and show similar immunomodulatory effects. Aerosol inhalation can stimulate the cellular immune response of the body through mucosal immunity to regulate gas, which can lead to airway inflammation and hyperresponsiveness. The present experimental study showed that both co-treatment and post-treatment with $M$. vaccae inhalation can reduce airway responsiveness and inflammation and inhibit $\gamma \delta \mathrm{T} 17$ cells differentiation and $\mathrm{IL}-17$ secretion. Correlation analysis between the prevention and the treatment groups showed that Jagged1 mRNA expression was correlated with $\gamma \delta T 17$ cells percentage, which suggested that atomized cow-related Mycobacterium can inhibit the production of $\gamma \delta T 17$ cells.

Many signaling pathways have been reported to be involved in the pathogenesis of asthma, including the Notch signaling pathway. This is an evolutionary conserved signaling pathway that plays key roles in the regulation of cell differentiation, development, proliferation, and survival (28). Although delta ligands are associated with the development of Th1 cells, Jagged ligands contribute to the development of Th2 cells. The main features of asthma are Th2 induction, Th1 cells reduction, and imbalance in Th1/Th2 ratio, in addition to excessive mucin secretion, airway inflammation, hyperresponsiveness, and

\section{References}

1. Asthma Section, Respiratory Disease Branch, Chinese Medical Association. Guidelines for the prevention and treatment of bronchial Asthma (2016 Edition) [in Chinese]. Chin J Tuberculosis Resp Dis 2016; 39: 675-697, doi: 10.3760/cma.j.issn.1001-0939.2016.09.007.

2. Al-Daghri NM, Alokail MS, Draz HM, Abd-Alrahman SH, Yakout SM, Clerici M. Th1/Th2 cytokine pattern in Arab children with severe asthma. Int J Clin Exp Med 2014; 7: 2286-2291.

3. Cheng M, Hu S. Lung-resident $\gamma \delta \mathrm{T}$ cells and their roles in lung diseases. Immunology 2017; 151: 375-384, doi: 10.1111/imm.12764.

4. Glanville N, Message SD, Walton RP, Pearson RM, Parker $\mathrm{HL}$, Laza-Stanca $\mathrm{V}$, et al. $\gamma \delta \mathrm{T}$ cells suppress inflammation and disease during rhinovirus-induced asthma exacerbations. remodeling. Many studies have shown that Notch signaling pathway can induce Th2-type cell differentiation and participate in the pathogenesis of asthma (29-32). When the body is infected by allergens, such as bacteria and viruses, it triggers a specific immune response through the antigen-presenting cells (APC). These cells present information to peripheral $\mathrm{T}$ cells and induce peripheral CD4 + T cells to differentiate into the Th1 subtype. T cell signaling is accomplished by the Notch signaling pathway, which plays key roles in directing Th1 and Th2 differentiation (33). Amsen et al. (28) reviewed evidence suggesting that the Notch pathway can mediate signals, and how Notch instructs Th-cell differentiation during normal and pathological immune responses. The Notch signaling pathway has been shown to be involved in the pathogenesis of allergic airway inflammation and is considered a new therapeutic target for asthma patients (32). Recent studies have reported that Jagged1 can lead to increased Th cell differentiation and is involved in airway inflammatory responses $(18,19)$. Indeed, studies have shown that silencing Jagged1 expression in asthma can reduce airway allergic reactions, inhibit Th2 cytokine secretion, and thus correct the imbalance in the Th1/Th2 cell ratio (34).

In conclusion, our results showed that nebulization of $M$. vaccae can reduce airway inflammation in asthmatic mice by regulating $\gamma \delta$ T17-based IL- 17 secretion through the downregulation of Jagged1. The regulation of $\gamma \delta \mathrm{T} 17$ by Jagged bacillus may be one of the target pathways for new asthma treatments. However, these results were obtained from animal models and tests in humans must be performed to validate them.

\section{Acknowledgments}

We are grateful for the support from The National Nature Science Foundation of China (No. 81470230) and Foundation of Guangxi (China) (No.14124003-7).
Mucosal Immunol 2013; 6: 1091-1100, doi: 10.1038/mi. 2013.3

5. Zhong F, Cui D, Tao H, Du H, Xing C. IL-17A-producing $T$ cells and associated cytokines are involved in the progression of gastric cancer. Oncol Rep 2015; 34: 2365-2374, doi: 10.3892/or.2015.4246.

6. Nakada EM, Shan J, Kinyanjui MW, Fixman ED. Adjuvantdependent regulation of interleukin-17 expressing $\gamma \delta \mathrm{T}$ cells and inhibition of Th2 responses in allergic airways disease. Respir Res 2014; 15: 90, doi: 10.1186/s12931-014-0090-5.

7. Chan AJ, Alikhan MA, Odobasic D, Gan PY, Khouri MB, Steinmetz OM, et al. Innate IL-17A-producing leukocytes promote acute kidney injury via inflammasome and Toll-like receptor activation. Am J Pathol 2014; 184: 1411-1418, doi: 10.1016/j.ajpath.2014.01.023. 
8. Silva MJ, Santana MBR, Tosta BR, Espinheira RP, Alcantara-Neves NM, Barreto ML, et al. Variants in the IL17 pathway genes are associated with atopic asthma and atopy makers in a South American population. Allergy Asthma Clin Immunol 2019; 15: 28, doi: 10.1186/s13223-019-0340-7.

9. Whitehead GS, Kang HS, Thomas SY, Medvedev A, Karcz TP, Izumi G, et al. Therapeutic suppression of pulmonary neutrophilia and allergic airway hyperresponsiveness by an ROR $\gamma$ t inverse agonist. JCl insight 2019; 5: e125528, doi: $10.1172 /$ jci.insight. 125528 .

10. Choy DF, Hart KM, Borthwick LA, Shikotra A, Nagarkar DR, Siddiqui $\mathrm{S}$, et al. TH2 and TH17 inflammatory pathways are reciprocally regulated in asthma. Sci Transl Med 2015; 7: 301ra129, doi: 10.1126/scitransImed.aab3142.

11. Papotto PH, Ribot JC, Silva-Santos B. IL-17(+) $\gamma \delta \mathrm{T}$ cells as kick-starters of inflammation. Nat immunol 2017; 18: 604-611, doi: 10.1038/ni.3726.

12. Zhang J, Li C, Guo S. Effects of inhaled inactivated Mycobacterium phlei on airway inflammation in mouse asthmatic models. J Aerosol Med Pulm Drug Deliv 2012; 25: 96-103, doi: 10.1089/jamp.2011.0904.

13. Guo SJ, Li CQ, Huang $X Q$, Jiang $X H$, Wu GH,Wang $H Z$. Clinical research on the treatment of moderate bronchial asthma with inhaled inactivated-Mycobacterium phlei [in Chinese]. Chin J Emergen Med 2011; 20: 413-417, doi: 10.3760/cma.j.issn.1671-0282.2011.04.018.

14. Ming M, Li C, Luo Z, Lv S, Sun Q. The effect of inhaled inactivated Mycobacterium phlei as a treatment for asthma. Mol Med Rep. 2017; 15: 777-783, doi: 10.3892/mmr.2016. 6087.

15. Shibata K, Yamada H, Sato T, Dejima T, Nakamura M, Ikawa $\mathrm{T}$, et al. Notch-Hes1 pathway is required for the development of IL-17-producing $\gamma \delta$ T cells. Blood 2011; 118: 586-593, doi: 10.1182/blood-2011-02-334995

16. Nieuwenhuis MA, Vonk JM, Himes BE, Sarnowski C, Minelli C, Jarvis D, et al. PTTG1IP and MAML3, novel genomewide association study genes for severity of hyperresponsiveness in adult Asthma. Allergy 2017; 72: 792-801, doi: 10.1111/all.13062.

17. Zhang S, Loch AJ, Radtke F, Egan SE, Xu K. Jagged1 is the major regulator of Notch-dependent cell fate in proximal airways. Dev Dyn 2013; 242: 678-686, doi: 10.1002/dvdy. 23965.

18. Xia M, Harb H, Saffari A, Sioutas C, Chatila TA. A Jagged 1Notch 4 molecular switch mediates airway inflammation induced by ultrafine particles. J Allergy Clin Immunol 2018; 142: 1243-1256, doi: 10.1016/j.jaci.2018.03.009.

19. Tindemans I, Lukkes M, de Bruijn MJW, Li BWS, van Nimwegen M, Amsen D, et al. Notch signaling in T cells is essential for allergic airway inflammation, but expression of the Notch ligands Jagged 1 and Jagged 2 on dendritic cells is dispensable. J Allergy Clin Immunol 2017; 140: 10791089, doi: 10.1016/j.jaci.2016.11.046.

20. Liu LL, Li FH, Zhang Y, Zhang XF, Yang J. Tangeretin has anti-asthmatic effects via regulating PI3K and Notch signaling and modulating Th1/Th2/Th17 cytokine balance in neonatal asthmatic mice. Braz J Med Biol Res 2017; 50: e5991, doi: 10.1590/1414-431x20175991.

21. Guan AL, He T, Shao YB, Chi YF, Dai HY, Wang Y, et al. Role of Jagged1-Hey1 signal in angiotensin II-induced impairment of myocardial angiogenesis. Chin Med J (Engl) 2017; 130: 328-333, doi: 10.4103/0366-6999.198928.

22. Xia W, Bai J, Wu X, Wei Y, Feng S, Li L, et al. Interleukin17A promotes MUC5AC expression and goblet cell hyperplasia in nasal polyps via the Act1-mediated pathway. PloS One 2014; 9: e98915, doi: 10.1371/journal.pone. 0098915.

23. Peters $\mathrm{M}$, Kohler-Bachmann $\mathrm{S}$, Lenz-Habijan $\mathrm{T}$, Bufe A. Influence of an allergen-specific Th17 response on remodeling of the airways. AM J Respir Cell Mol Biol 2016; 54: 350358, doi: 10.1165/rcmb.2014-04290C.

24. Murdoch JR, Gregory LG, Lloyd CM. $\gamma \delta T$ cells regulate chronic airway inflammation and development of airway remodelling. Clin Exp Allergy 2014; 44: 1386-1398, doi: 10.1111/cea.12395.

25. Roark CL, Simonian PL, Fontenot AP, Born WK, O'Brien RL. Gammadelta T cells: an important source of IL-17. Curr Opin Immunol 2008; 20: 353-357, doi: 10.1016/j.coi.2008.03.006.

26. Yang X, Zhang JH, Deng WS, Li CQ. Imbalance of $\gamma \delta \mathrm{T} T 17 /$ $\gamma \delta \mathrm{T}$ Treg cells in the pathogenesis of allergic asthma induced by ovalbumin. Braz J Med Biol Res 2018; 51: e7127, doi: 10.1590/1414-431x20187127.

27. Li CQ, Xu YJ, Yang DL, Shi HZ, Liu XS, Xiong WN, et al. A study of helper T cell (Th)1/Th2 immune response pattern of $\gamma \delta \mathrm{T}$ cells in asthma [in Chinese]. Zhonghua Nei Ke Za Zhi 2004; 43: 342-344.

28. Amsen D, Antov A, Flavell RA. The different faces of Notch in T-helper-cell differentiation. Nat Rev Immunol 2009; 9: 116-124, doi: 10.1038/nri2488.

29. Lee CC, Wang CC, Huang HM, Lin CL, Leu SJ, Lee YL. Corrigendum to "ferulic acid induces Th1 responses by modulating the function of dendritic cells and ameliorates Th2-mediated allergic airway inflammation in mice". Evid Based Complement Alternat Med 2017; 2017: 1039829, doi: 10.1155/2015/678487.

30. Damle SR, Martin RK, Cockburn CL, Lownik JC, Carlyon JA, Smith AD, et al. ADAM10 and Notch1 on murine dendritic cells control the development of type 2 immunity and IgE production. Allergy 2018; 73: 125-136, doi: 10.1111/all. 13261.

31. Lee CC, Lin CL, Leu SJ, Lee YL. Overexpression of Notch ligand Delta-like- 1 by dendritic cells enhances their immunoregulatory capacity and exerts antiallergic effects on Th2mediated allergic asthma in mice. Clin Immunol 2018; 187 : 58-67, doi: 10.1016/j.clim.2017.10.005.

32. KleinJan A, Tindemans I, Montgomery JE, Lukkes M, Bruijn MJW, Nimwegen $M$, et al. The Notch pathway inhibitor stapled alpha-helical peptide derived from mastermind-like 1 (SAHM1) abrogates the hallmarks of allergic Asthma. J Allergy Clin Immunol 2018; 142: 76-85.e8, doi: 10.1016/ j.jaci.2017.08.042

33. Jiang S, Han S, Chen J, Li X, Che H. Inhibition effect of blunting Notch signaling on food allergy through improving TH1/TH2 balance in mice. Ann Allergy Asthma Immunol 2017; 118: 94-102, doi: 10.1016/j.anai.2016.10.024.

34. Okamoto M, Matsuda H, Joetham A, Lucas JJ, Domenico J, Yasutomo K, et al. Jagged1 on dendritic cells and Notch on CD4 + T cells initiate lung allergic responsiveness by inducing IL-4 production. J Immunol 2009; 183: 2995-3003, doi: 10.4049/jimmunol.0900692. 